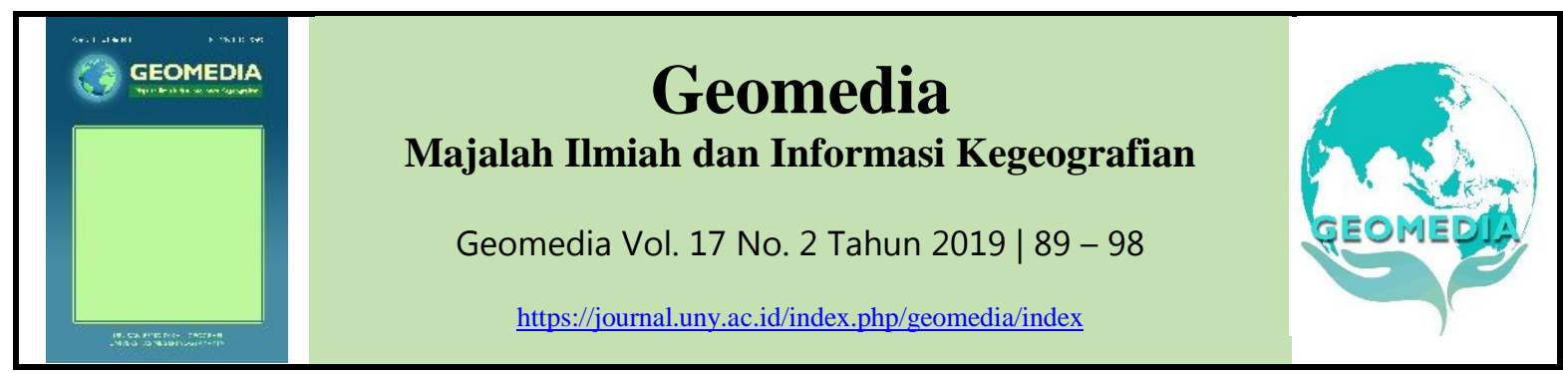

\title{
Analisis perkembangan sertipikat hak atas tanah nelayan dan arahan pemanfaatan ruang wilayah pesisir di Kecamatan Kragan Kabupaten Rembang
}

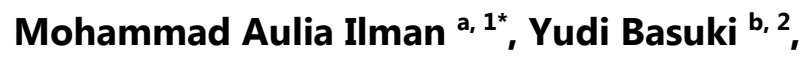 \\ a Magister Perencanaan Wilayah dan Kota, Universitas Diponegoro, Semarang, Indonesia \\ b Dosen Magister Perencanaan Wilayah dan Kota, Universitas Diponegoro, Semarang, Indonesia \\ ${ }^{1}$ ulie.kudus@gmail.com*; ${ }^{2}$ yudibasuki@yahoo.com \\ ${ }^{*}$ korespondensi penulis
}

\begin{tabular}{ll}
\hline Informasi artikel \\
\hline Sejarah artikel & \\
Diterima $\quad:$ \\
Revisi $\quad:$ \\
Dipublikasikan $\quad:$ \\
\hline
\end{tabular}

Kata kunci:

Evaluasi

Sertipikat Hak Atas Tanah Nelayan

Rencana Tata Ruang Wilayah

Pesisir

\begin{abstract}
A B S T R A K
Penelitian ini bertujuan untuk menganalisis perkembangan sertipikat hak atas tanah nelayan dan arahan pemanfaatan ruang wilayah pesisir di Kecamatan Kragan Kabupaten Rembang. Penelitian ini didasarkan pada kegiatan sertipikasi hak atas tanah nelayan di Kecamatan Kragan selama 5 (Lima) tahun yaitu Tahun 2013 sampai dengan 2018. Metode penelitian digunakan metode penelitian kuantitatif dengan teknik analisis dalam SIG (Sistem Informasi Geografis) yaitu overlay peta. Overlay peta yang dilakukan yaitu antara peta bidang tanah sertipikasi hak atas tanah nelayan dengan peta rencana pola ruang wilayah pesisir. Dari hasil penelitian menunjukkan bahwa perkembangan sertipikat hak atas tanah nelayan mengalami trend kenaikan. Secara keseluruhan, luas bidang tanah sertipikat hak atas tanah nelayan yang berada pada arahan kawasan budidaya adalah seluas 140.689 M2 atau 82,9\% sedangkan berada di arahan kawasan lindung adalah seluas 28.919 M2 atau 17,1 \%.
\end{abstract}

\section{Keywords:}

Evaluation

Fisherman land registration

Spatial plan

Coastal Area

\section{A B S T R A C T}

This study aims to analyze the development of fishermen land registration and the coastal land use direction in Kragan Sub-district, Rembang Regency. This research is based on the activity of fishermen land registration in Kragan Subdistrict for 5 (five) years, from 2013 to 2018. The research method used is quantitative research methods with analytical techniques in GIS (Geographic Information Systems), named map overlay. Map overlay is carried out between the map of land parcels with a map of the coastal area spatial pattern. From the results of the study showed that the development of fishermen land registration experienced an upward trend. Overall, the total area of land with fishermen land registration who are in the direction of the cultivation area is $140,689 \mathrm{M} 2$ or $82.9 \%$ while in the direction of the protected area is $28,919 \mathrm{M} 2$ or $17.1 \%$.

(C) 2019 (Mohammad Aulia Ilman \& Yudi Basuki). All Right Reserved

\section{Pendahuluan}

Perkembangan wilayah pesisir dapat menimbulkan manfaat yang besar bagi pembangunan tetapi di lain sisi juga berdampak negatif terhadap lingkungan memerlukan upaya perencanaan penataan ruang sebagai upaya mengantisipasi konflik penggunaan dan degenerasi lingkungan pesisir (Rahmawati, 2016). Undang-Undang No. 27 Tahun 2007 tentang Pengelolaan Wilayah Pesisir 
dan Pulau-Pulau Kecil pasal 1 ayat 2 mendefinisikan pengertian wilayah pesisir sebagai wilayah peralihan antara ekosistem darat dan laut yang saling berinteraksi, dimana ke arah 12 mil dari garis pantai untuk provinsi dan sepertiga dari wilayah laut itu untuk kabupaten/kota ke arah darat batas administrasi kabupaten/kota. Pengelolaan wilayah pesisir tidak akan berjalan efektif tanpa adanya penataan ruang wilayah pesisir yang terintegrasi (Vugteveen et al., 2014). Penataan ruang wilayah pesisir mempunyai peranan penting untuk meningkatkan kesejahteraan masyarakat pesisir (Cigliano et al., 2015) sekaligus melindungi ekosistem yang ada didalamnya atau berfungsi sebagai konservasi (Jefferson et al., 2015). Dampak lain yang dapat ditimbulkan antara lain: kerusakan lingkungan dan ekologi (Dunstan et al., 2016).

Waryanta (2016) juga mengungkapkan bahwa perencanaan penataan wilayah pesisir belum mempertimbangkan faktor penggunaan, pemanfaatan, penguasaan dan kepemilikan tanah sehingga untuk melengkapinya diperlukan kebijakan penataan pertanahan di wilayah pesisir. Penataan pertanahan adalah upaya penataan aspek fisik pemanfaatan tanah dan penataan aspek hukum penguasaan tanah untuk menunjang pelaksanaan pembangunan (Sutaryono, 2016). Penataan pertanahan dalam penataan wilayah pesisir juga berfungsi untuk mengantisipasi alih fungsi lahan yang tidak sesuai dengan eksisting penggunaan tanah (Ferrol et al., 2015), konflik dan sengketa pertanahan serta konflik sosial akibat konflik kepentingan penguasaan tanah hingga penguasaan dan pemilikan tanah secara ilegal (Wakker et al., 2003). Kegiatan penataan penggunaan tanah secara berencana merupakan upaya pengendalian penggunaan tanah untuk mewujudkan kemakmuran rakyat yang sebesarbesarnya. Sebaliknya, kegiatan penataan penguasaan tanah merupakan suatu upaya untuk mengatur pemberian status hukum atas tanah yang diarahkan agar pemanfaatannya dapat mewujudkan keadilan sosial bagi seluruh masyarakat.

Flego dan Roić (2018) mengungkapkan bahwa adanya peningkatan aktivitas di wilayah pesisir akan menghasilkan peningkatan jumlah pendaftaran tanah yang diterbitkan di wilayah pesisir. Salah satu program pertanahan yang dikhususkan untuk wilayah pesisir adalah sertipikasi hak atas tanah nelayan. Kegiatan sertifikasi hak atas tanah nelayan dimaksudkan untuk memberikan kepastian hukum hak atas tanah nelayan dan pelaku usaha penangkapan ikan. Selain untuk permodalan bagi nelayan, dengan adanya sertipikasi hak atas tanah nelayan dapat dijadikan sebagai analisis untuk melihat perkembangan pemanfaatan ruang di wilayah pesisir.

Kepemilikan hak atas tanah seharusnya menjadi faktor penting dalam perencanaan tata ruang wilayah pesisir berdasarkan aspek pertanahan. Didalam Peraturan Daerah Kabupaten Rembang Nomor 14 Tahun 2011 tentang Rencana Tata Ruang Wilayah Kabupaten Rembang Tahun 2011-2031 belum menunjukkan bahwa aspek pertanahan terutama kepemilikan hak atas tanah telah sesuai dengan arah pemanfaatan ruang wilayah pesisir di Kabupaten Rembang. Hal ini terlihat dari adanya kepemilikan hak atas tanah yang berada dalam arahan pemanfaatan ruang wilayah pesisir untuk kawasan lindung terutama sempadan pantai

Kecamatan Kragan merupakan salah satu kecamatan di Kabupaten Rembang yang memiliki wilayah pesisir yang cukup luas. Terdiri dari 27 desa dengan 13 desa yang merupakan desa di wilayah pesisir Kabupaten Rembang. Selain itu Kecamatan Kragan merupakan kecamatan dengan jumlah program pertanahan yaitu sertipikasi hak atas tanah nelayan terbanyak di Kabupaten Rembang. Arahan pemanfaatan ruang di Kecamatan Kragan adalah sebagai kawasan budidaya yang berupa pemukiman, industri menengah, perikanan dan pertanian. Selain itu terdapat arahan pemanfaatan ruang sebagai kawasan lindung berupa sempadan pantai. 
Sertipikat hak atas tanah nelayan menjamin kepastian hukum kepemilikan tanah (Ramdani, 2017). Dengan adanya kepastian hukum tersebut maka nelayan dapat mengembangkan usahanya untuk meningkatkan kesejahteraannya. Namun dalam arahan pemanfaatan ruang terdapat arahan kawasan lindung dimana aktivitas budidaya dibatasi. Hal ini menimbulkan permasalahan manakala terdapat sertipikat hak atas tanah nelayan yang berada di kawasan lindung sehingga perlu dilakukan penelitian untuk mengetahui perkembangan sertipikat hak atas tanah nelayan dan arahan pemanfaatan ruang wilayah pesisir.

Berdasarkan latar belakang tersebut, maka pertanyaan penelitian yang diangkat adalah bagaimana perkembangan sertipikat hak atas tanah nelayan dan arahan pemanfaatan ruang wilayah pesisir di Kecamatan Kragan Kabupaten Rembang?.

Tujuan dilakukan penelitian ini yaitu untuk menganalisis perkembangan sertipikat hak atas tanah nelayan dan arahan pemanfaatan ruang wilayah pesisir di Kecamatan Kragan Kabupaten Rembang. Penelitian ini ditekankan pada perkembangan sertipikat hak atas tanah nelayan selama 5 (Lima) tahun yaitu tahun 2013 sampai dengan 2018 dan rencana pola ruang wilayah pesisir yaitu kawasan budidaya dan kawasan lindung berdasarkan Peraturan Daerah Kabupaten Rembang Nomor 14 Tahun 2011 tentang Rencana Tata Ruang Wilayah Kabupaten Rembang Tahun 2011-2031

\section{Metode}

Pendekatan penelitian yang digunakan untuk mengkaji penelitian ini adalah pendekatan yang bersifat deduktif. Teknik pengumpulan data dalam penelitian ini digolongkan menjadi 2 (dua), yaitu teknik pengumpulan data primer dan teknik pengumpulan data sekunder. Teknik pengumpulan data primer terdiri observasi lapangan dan wawancara mendalam sedangkan Teknik pengumpulan data sekunder dilakukan dengan telaah dokumen. Variabel yang digunakan antara lain : jumlah sertipikat, letak dan luas bidang tanah, peruntukan tanah dan rencana pola ruang wilayah.

Metode penelitian yang digunakan adalah metode penelitian kuantitatif. Metode penelitian kuantitatif ditekankan pada teknik analisis dalam SIG (Sistem Informasi Geografis) yaitu overlay peta. Teknik analisis overlay peta merupakan salah satu teknik analisis dalam SIG (Sistem Informasi Geografis) dengan menempatkan grafis satu peta diatas grafis peta yang lain. Overlay peta yang dilakukan yaitu antara peta bidang tanah sertipikasi hak atas tanah nelayan di Kecamatan Kragan, Kabupaten Rembang dengan peta rencana pola ruang wilayah pesisir yang terdapat dalam Rencana Tata Ruang Wilayah Kabupaten Rembang. Berdasarkan Undang-undang Nomor 5 Tahun 1960 digunakan parameter bahwa lokasi bidang tanah sertipikat harus berada pada arahan kawasan budidaya. Berdasarkan uraian tersebut maka dibuat klasifikasi yang ditunjukkan oleh Tabel 1 berikut :

Tabel 1. Klasifikasi Sertipikat Hak Atas Tanah Nelayan Dan Arahan Pemanfaatan Ruang Wilayah

\begin{tabular}{ccc}
\hline No & $\begin{array}{c}\text { Klasifikasi } \\
\text { Sertipikat }\end{array}$ & $\begin{array}{c}\text { Arahan Pemanfaatan } \\
\text { Ruang Wilayah }\end{array}$ \\
\hline 1. & S1 & $\begin{array}{c}\text { Arahan Kawasan } \\
\text { Budidaya }\end{array}$ \\
\hline 2. & S2 & $\begin{array}{c}\text { Arahan Kawasan } \\
\text { Lindung }\end{array}$ \\
\hline
\end{tabular}

Teknik analisis overlay peta didapatkan hasil yaitu persentase luas sertipikat hak atas tanah nelayan berdasarkan arahan kawasan budidaya dan arahan kawasan lindung wilayah pesisir di Kecamatan Kragan Kabupaten Rembang. Proses overlay peta ditunjukkan oleh Gambar 1.

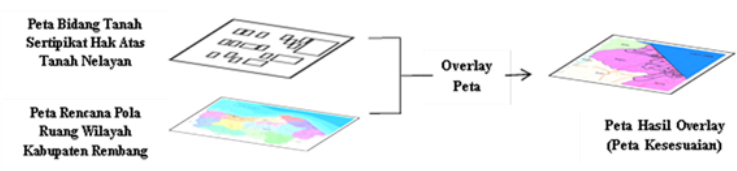

Gambar 1. Proses Overlay Peta 
Selain itu, dilakukan teknik analisis deskriptif kuantitatif yang digunakan untuk mengidentifikasi perkembangan sertipikasi hak atas tanah nelayan di Kecamatan Kragan, Kabupaten Rembang dan arahan pemanfaatan ruang wilayah pesisir yang ada didalam rencana tata ruang wilayah Kabupaten Rembang. Analisis deskriptif kuantitatif dilakukan dengan telaah dokumen yang bersumber dari dokumen atau arsip yang terdapat dari instansi terkait terutama diambil dari Kantor Pertanahan Kabupaten Rembang dan Dinas Pekerjaan Umum dan Penataan Ruang Kabupaten Rembang.

\section{Hasil dan pembahasan}

Dalam penelitian ini dilakukan identifikasi terhadap jumlah dan luas sertipikat hak atas tanah nelayan di Kecamatan Kragan Kabupaten Rembang Tahun 2013 sampai dengan Tahun 2018. Adapun tabel Jumlah dan Luas Sertipikat Hak Atas Tanah Nelayan Di Kecamatan Kragan Kabupaten Rembang ditunjukkan oleh Tabel 2 berikut:

Tabel 2. Jumlah dan Luas Sertipikat Hak Atas Tanah Nelayan Di Kecamatan Kragan Kabupaten

\begin{tabular}{|c|c|c|c|c|}
\hline \multicolumn{5}{|c|}{ Rembang } \\
\hline No & Tahun & Nama Desa & $\begin{array}{l}\text { Jumlah } \\
\text { Sertipikat }\end{array}$ & $\begin{array}{l}\text { Luas } \\
\left(\mathrm{m}^{2}\right)\end{array}$ \\
\hline 1 & 2013 & $\begin{array}{l}\text { Pandangan } \\
\text { Wetan }\end{array}$ & 54 & 5.227 \\
\hline \multirow[t]{3}{*}{2} & 2014 & Kebloran & 34 & 3.602 \\
\hline & & Plawangan & 68 & 13.482 \\
\hline & & Tegalmulyo & 50 & 21.139 \\
\hline \multirow[t]{2}{*}{3} & 2015 & Sumbersari & 50 & 19.173 \\
\hline & & Tanjungan & 50 & 14.156 \\
\hline \multirow[t]{3}{*}{4} & 2016 & Balongmulyo & 25 & 11.731 \\
\hline & & Kragan & 50 & 5.747 \\
\hline & & Plawangan & 40 & 6.820 \\
\hline \multirow[t]{4}{*}{5} & 2017 & Karanglincak & 51 & 11.259 \\
\hline & & Sumurtawang & 10 & 7.344 \\
\hline & & Tanjungan & 55 & 9.734 \\
\hline & & Tegalmulyo & 33 & 8.860 \\
\hline \multirow[t]{5}{*}{6} & 2018 & Karanglincak & 50 & 6.661 \\
\hline & & Plawangan & 80 & 12.316 \\
\hline & & Tanjungan & 32 & 6.181 \\
\hline & & Tegalmulyo & 38 & 6.176 \\
\hline & & Jumlah & 770 & 169.608 \\
\hline
\end{tabular}

Berdasarkan tabel diatas diketahui bahwa di Kecamatan Kragan Kabupaten Rembang selama Tahun 2013 sampai dengan Tahun 2018 telah dilaksanakan kegiatan sertipikasi hak atas tanah nelayan sebanyak 770 sertipikat dan luas bidang tanah sertipikat seluas 169.608 M2. Peruntukan tanah didominasi untuk perumahan. Kegiatan sertipikasi hak atas tanah nelayan dilaksanakan di 10 (sepuluh) desa antara lain : Desa Pandangan Wetan, Desa Kebloran, Desa Plawangan, Desa Tegalmulyo, Desa Sumbersari, Desa Tanjungan, Desa Balongmulyo, Desa Kragan, Desa Karanglincak dan Desa Sumurtawang. Desa dengan jumlah sertipikat hak atas tanah nelayan terbanyak adalah Desa Plawangan sebanyak 188 sertipikat sedangkan desa dengan jumlah sertipikat paling sedikit adalah Desa Sumurtawang sebanyak 10 sertipikat. Luas bidang tanah sertipikat hak atas tanah nelayan terluas berada di Desa Tegalmulyo seluas 36.175 M2 sedangkan luas tersempit berada di Desa Kebloran seluas 3.602 M2. Berdasarkan tabel diatas dapat dibuat grafik seperti ditunjukkan oleh Gambar 2.

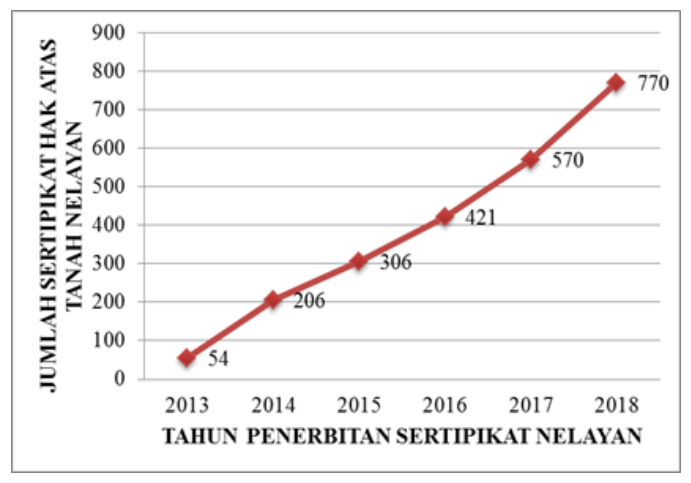

Gambar 2. Grafik Perkembangan Jumlah Sertipikat Hak Atas Tanah Nelayan Di Kecamatan Kragan Kabupaten Rembang

Berdasarkan Gambar 2, diketahui bahwa pada Tahun 2013-2018, Kecamatan Kragan Kabupaten Rembang mengalami trend kenaikan jumlah sertipikat hak atas tanah nelayan. Hal ini menunjukkan bahwa minat dan partisipasi masyarakat nelayan di Kecamatan Kragan Kabupaten Rembang untuk mengikuti kegiatan 
sertipikasi hak atas tanah nelayan tergolong tinggi. Tabel 3 berikut adalah data luas sertipikat hak atas tanah nelayan per tahun.

Tabel 3. Luas Sertipikat Hak Atas Tanah Nelayan

Per Tahun Di Kecamatan Kragan Kabupaten Rembang Per Tahun

\begin{tabular}{|c|c|c|c|c|}
\hline \multirow[t]{2}{*}{ No } & \multirow[t]{2}{*}{ Tahun } & \multicolumn{2}{|c|}{$\begin{array}{l}\text { Luas Per Tahun } \\
\text { (M2) }\end{array}$} & \multirow{2}{*}{$\begin{array}{l}\text { Total Luas } \\
\text { Per Tahun } \\
\text { (M2) }\end{array}$} \\
\hline & & S1 & S2 & \\
\hline 1. & 2013 & 5.147 & 80 & 5.227 \\
\hline 2. & 2014 & 31.717 & 6.506 & 38.223 \\
\hline 3. & 2015 & 29.120 & 4.209 & 33.329 \\
\hline 4. & 2016 & 17.364 & 6.934 & 24.298 \\
\hline 5. & 2017 & 34.174 & 3.023 & 37.197 \\
\hline 6. & 2018 & 23.167 & 8.167 & 31.334 \\
\hline \multicolumn{2}{|c|}{ JUMLAH } & 140.689 & 28.919 & 169.608 \\
\hline
\end{tabular}

Berdasarkan tabel diatas diketahui bahwa pada Tahun 2013-2018 dimana Kecamatan Kragan Kabupaten Rembang terdapat kegiatan sertipikasi hak atas tanah nelayan adalah fluktuatif. Luas sertipikat hak atas tanah nelayan terbesar terjadi pada Tahun 2014 seluas 38.223 M2 sedangkan luas sertipikat hak atas tanah nelayan tersempit terjadi pada Tahun 2013 sebanyak 5.227 M2. Pada Tahun 2014, luas sertipikat hak atas tanah nelayan yang paling besar dikarenakan terdapat sertipikat hak atas tanah dengan peruntukan tanah untuk tambak di Desa Tegalmulyo dengan luas tanah yang besar dimana rata-rata peruntukan tanah sertipikat hak atas tanah nelayan di wilayah penelitian adalah perumahan. Tahun 2013 merupakan tahun dengan luas sertipikat hak atas tanah nelayan yang paling sempit dikarenakan jumlah sertipikat hak atas tanah nelayan yang diterbitkan sedikit yaitu 54 sertipikat. Berdasarkan hal tersebut dapat disimpulkan bahwa jumlah sertipikat hak atas nelayan yang terbit tidak berbanding lurus dengan luas sertipikat hak atas nelayan. Hal ini tergantung dari peruntukan tanah yang ada pada sertipikat hak atas nelayan tersebut. Gambar 4 berikut menunjukkan sebaran bidang tanah sertipikat hak atas tanah nelayan di Kecamatan Kragan Kabupaten Rembang.



Gambar 4. Peta Sebaran Bidang Tanah Sertipikat Hak Atas Tanah Nelayan di Kecamatan Kragan Kabupaten Rembang 
Dalam penelitian ini juga dilakukan Identifikasi arahan pemanfaatan ruang berdasarkan rencana tata ruang wilayah pesisir yang termuat dalam Peraturan Daerah Kabupaten Rembang Nomor 14 Tahun 2011 tentang Rencana Tata Ruang Wilayah Kabupaten Rembang Tahun 2011 - 2031. Rencana tata ruang wilayah pesisir merupakan hasil dari proses perencanaan tata ruang untuk melindungi dan melestarikan fungsi wilayah pesisir (Manaf, 2012). Di Kabupaten Rembang tidak terdapat dokumen atau arsip khusus yang membahas tentang rencana tata ruang pesisir akan tetapi rencana tata ruang pesisir tersebut termuat dalam rencana tata ruang wilayah Kabupaten Rembang secara umum. Dalam identifikasi arahan pemanfaatan ruang wilayah pesisir Di Kecamatan Kragan Kabupaten Rembang ditekankan pada rencana pola ruang wilayah pesisir. Rencana pola ruang wilayah meliputi arahan kawasan budidaya dan arahan kawasan lindung. Gambar 5 berikut menunjukkan peta rencana pola ruang wilayah di Kecamatan Kragan Kabupaten Rembang.

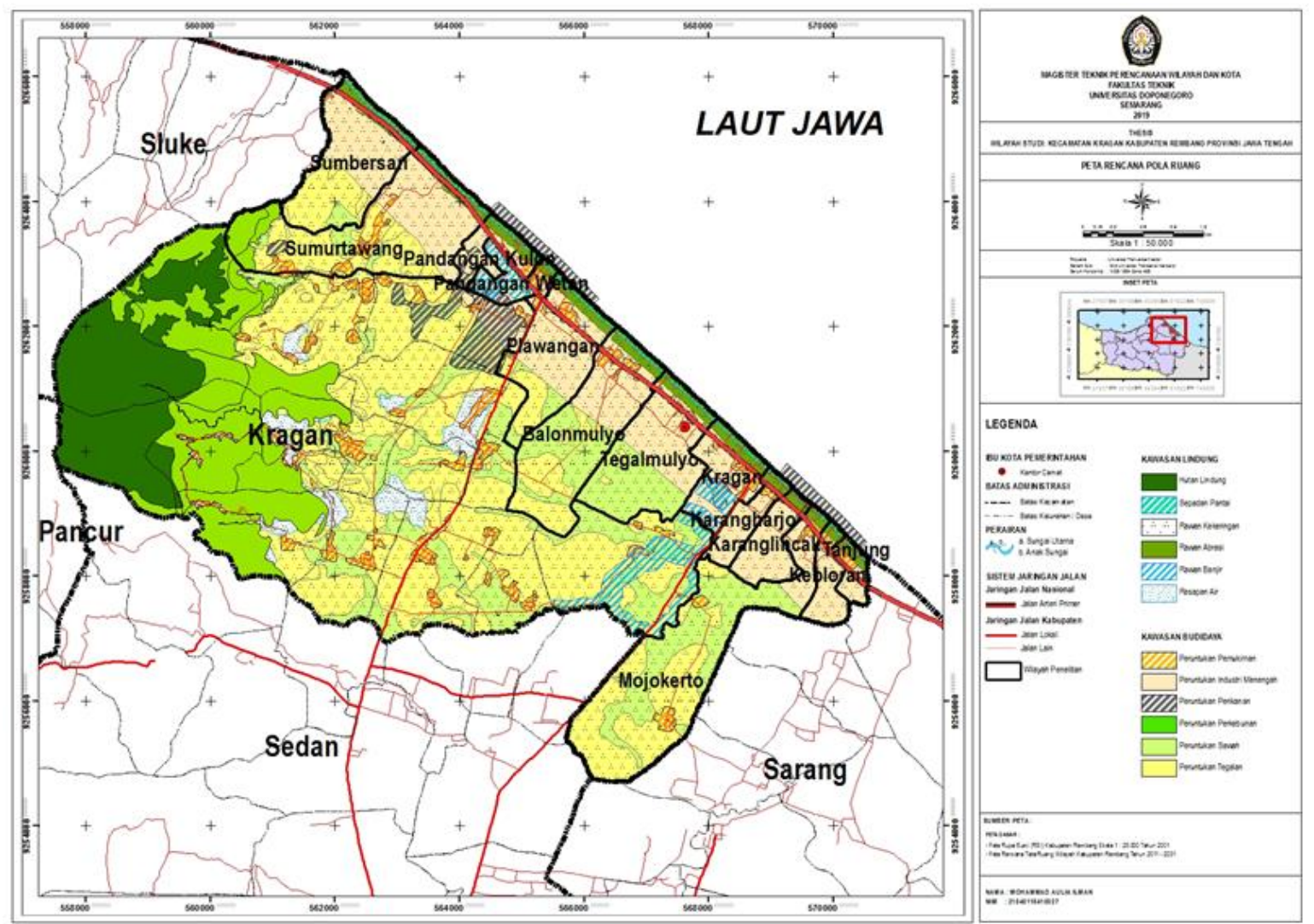

Gambar 5. Peta Rencana Pola Ruang Wilayah di Kecamatan Kragan Kabupaten Rembang

Berdasarkan peta rencana pola ruang wilayah di Kecamatan Kragan Kabupaten Rembang diketahui bahwa arahan kawasan lindung untuk pesisir yang ada pada wilayah penelitian adalah sempadan pantai, rawan abrasi, rawan kekeringan dan rawan banjir. Berbeda dengan Peraturan Menteri Agraria Dan Tata Ruang/Kepala Badan Pertanahan Nasional Republik Indonesia Nomor 1 Tahun 2018 Tentang Pedoman Penyusunan Rencana Tata Ruang Wilayah Propinsi, Kabupaten Dan Kota menyatakan bahwa kawasan rawan bencana yang tidak ditetapkan menjadi kawasan rawan bencana yang tingkat kerawanan dan berdampak paling tinggi bukan merupakan kawasan lindung sehingga kawasan rawan abrasi, kawasan rawan kekeringan dan kawasan rawan banjir bukan merupakan kawasan lindung. Hanya kawasan sempadan pantai yang merupakan arahan kawasan lindung pesisir di Kecamatan Kragan Kabupaten Rembang. 
Selain itu berdasarkan peta rencana pola ruang wilayah di Kecamatan Kragan Kabupaten Rembang diketahui bahwa arahan kawasan budidaya di Kecamatan Kragan Kabupaten Rembang terdiri dari kawasan peruntukan permukiman, peruntukan industri menengah, peruntukan perikanan, peruntukan pertanian dan peruntukan wisata. Selain itu kawasan-kawasan tersebut juga berada pada kawasan budidaya pesisir di wilayah penelitian. Kawasan budidaya pesisir yang menjadi objek dari sertipikasi hak atas tanah nelayan di wilayah penelitian adalah kawasan peruntukan permukiman dan kawasan peruntukan perikanan.

Analisis perkembangan sertipikat hak atas tanah nelayan dan rencana tata ruang wilayah pesisir di Kecamatan Kragan, Kabupaten Rembang dilakukan dengan overlay peta yaitu antara peta bidang tanah sertipikat hak atas tanah nelayan di Kecamatan Kragan Kabupaten Rembang dengan peta rencana pola ruang wilayah berdasarkan Rencana Tata Ruang Wilayah Kabupaten Rembang Tahun 2011-2031 Peta bidang tanah sertipikat hak atas nelayan didasarkan pada kegiatan sertipikasi hak atas tanah nelayan Tahun 2013-2018. Untuk peta rencana pola ruang wilayah pesisir digunakan kawasan sempadan pantai sebagai kawasan lindung. Analisis ini merupakan tahapan untuk menganalisis perkembangan sertipikat hak atas tanah nelayan dan rencana tata ruang wilayah pesisir di Kecamatan Kragan, Kabupaten Rembang berdasarkan parameter kawasan lindung pesisir yaitu sempadan pantai. Adapun tabel hasil analisis luas sertipikasi hak atas tanah nelayan dan arahan pemanfaatan ruang wilayah pesisir di Kecamatan Kragan, Kabupaten Rembang per tahun adalah ditujukkan oleh Tabel 4 berikut :

Tabel 4. Luas Sertipikasi Hak Atas Tanah Nelayan dan Arahan Pemanfaatan Ruang Wilayah Pesisir di Kecamatan Kragan, Kabupaten Rembang Tahun 2013 - 2018.

\begin{tabular}{|c|c|c|c|c|c|}
\hline \multirow[t]{2}{*}{ No } & \multirow[t]{2}{*}{ Tahun } & \multirow[t]{2}{*}{ Nama Desa } & \multicolumn{2}{|c|}{ Kategori (M2) } & \multirow[t]{2}{*}{ Luas (M2) } \\
\hline & & & S1 & S2 & \\
\hline 1. & 2013 & Pandangan Wetan & 5.147 & 80 & 5.227 \\
\hline \multirow[t]{3}{*}{2.} & 2014 & Kebloran & 2.307 & 1.295 & 3.602 \\
\hline & & Plawangan & 9.221 & 4.261 & 13.482 \\
\hline & & Tegalmulyo & 20.189 & 950 & 21.139 \\
\hline \multirow[t]{2}{*}{3.} & 2015 & Sumbersari & 17.033 & 2.140 & 19.173 \\
\hline & & Tanjungan & 12.087 & 2.069 & 14.156 \\
\hline \multirow[t]{3}{*}{4.} & 2016 & Balongmulyo & 11.731 & 0 & 11.731 \\
\hline & & Kragan & 1.339 & 4.408 & 5.747 \\
\hline & & Plawangan & 4.294 & 2.526 & 6.820 \\
\hline \multirow[t]{4}{*}{5.} & 2017 & Karanglincak & 10.698 & 561 & 11.259 \\
\hline & & Sumurtawang & 5.975 & 1.369 & 7.344 \\
\hline & & Tanjungan & 8.855 & 879 & 9.734 \\
\hline & & Tegalmulyo & 8.646 & 214 & 8.860 \\
\hline \multirow[t]{4}{*}{6.} & 2018 & Karanglincak & 5.930 & 731 & 6.661 \\
\hline & & Plawangan & 6.760 & 5.556 & 12.316 \\
\hline & & Tanjungan & 5.287 & 894 & 6.181 \\
\hline & & Tegalmulyo & 5.190 & 986 & 6.176 \\
\hline JUMLAH & & & 140.689 & 28.919 & 169.608 \\
\hline
\end{tabular}


Berdasarkan tabel diatas diketahui bahwa wilayah penelitian dengan kategori "S1" tertinggi adalah Desa Balongmulyo seluas $11.731 \mathrm{M} 2$ atau 100\%. Hal ini dapat diartikan bahwa semua bidang tanah sertipikat hak atas tanah nelayan di Desa Balongmulyo berada di arahan kawasan budidaya dan tidak ada bidang tanah sertipikat hak atas tanah nelayan yang berada didalam kawasan sempadan pantai. Untuk wilayah penelitian dengan kategori "S1" terendah adalah Desa Kragan seluas 1.339 M2 atau 23,3\%. Hal ini menunjukkan bahwa hanya sedikit bidang tanah sertipikat hak atas tanah nelayan yang berada di pola ruang wilayah dengan arahan kawasan budidaya dan berada diluar kawasan sempadan pantai. Berbanding terbalik untuk kategori "S2", dimana untuk kategori "S2" yang tertinggi adalah Desa Kragan seluas 4.408 M2 atau 76,7\% dan kategori "S2" yang terendah adalah Desa Balongmulyo seluas $0 \mathrm{M} 2$ atau $0 \%$. Baik untuk kategori "S1" dan "S2" di wilayah penelitian Desa Balongmulyo dan Desa Kragan didasarkan pada kegiatan sertipikasi hak atas tanah nelayan Tahun 2016. Gambar 6 menujukkan peta analisis luas setipikasi hak atas tanah nelayan dan arahan pemanfaatan ruang wilayah pesisir di Kecamatan Kragan, Kabupaten Rembang tahun 2018.

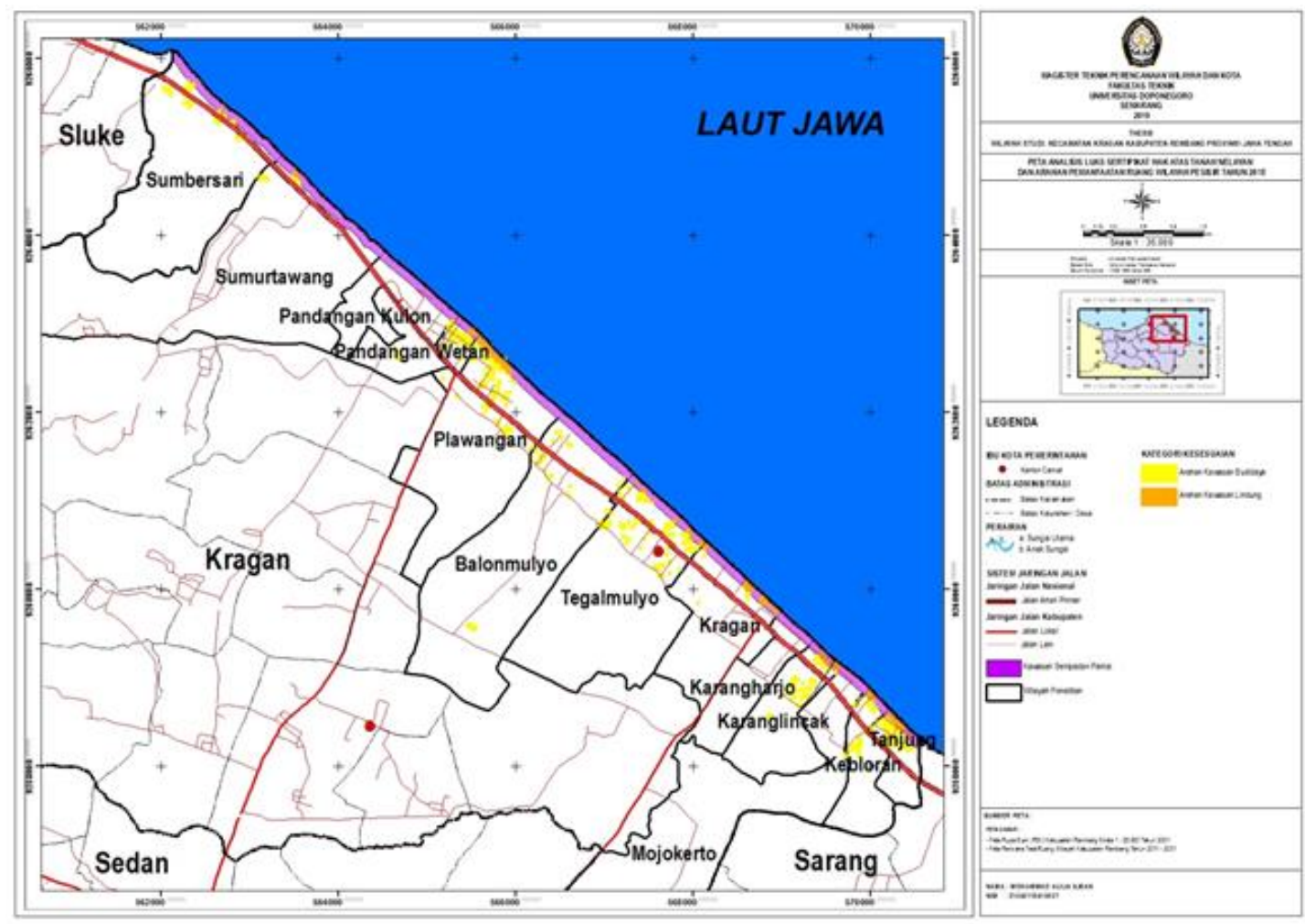

Gambar 6. Peta Analisis Luas Setipikasi Hak Atas Tanah Nelayan dan Arahan Pemanfaatan Ruang Wilayah Pesisir di Kecamatan Kragan, Kabupaten Rembang Tahun 2018

Selain itu dapat dilihat bahwa wilayah penelitian yang berpotensi terancam mengalami konflik penggunaan dan degenerasi lingkungan pesisir dikarenakan luas bidang tanah sertipikat hak atas tanah nelayan berada pada arahan kawasan lindung pesisir sempadan pantai yang terbesar antara lain: Desa Kragan, Desa Plawangan dan Desa Kebloran. Hal ini disebabkan oleh luas bidang tanah sertipikat hak atas tanah nelayan yang berada didalam kawasan sempadan pantai pada desa-desa tersebut yang besar. Diketahui juga bahwa peruntukkan tanah untuk sertipikat hak atas tanah nelayan di Desa Kragan, Desa Plawangan dan Desa Kebloran adalah perumahan sehingga dapat berpotensi merusak lingkungan dan ekologi (Dunstan et al., 2016) di 
wilayah pesisir yang seharusnya sebagai kawasan lindung sempadan pantai. Adanya alih fungsi lahan yang tidak sesuai dengan eksisting penggunaan tanah (Ferrol et al., 2015) akan mengancam keberlanjutan ekosistem didalamnya yang berfungsi sebagai konservasi wilayah pesisir (Jefferson et al., 2015).

Berdasarkan hal tersebut, maka didapatkan hasil luas sertipikat hak atas tanah nelayan dan arahan pemanfaatan ruang wilayah pesisir secara keseluruhan yang ditunjukkan oleh Tabel 5 berikut.

Tabel 5. Analisis Luas Sertipikat Hak Atas Tanah Nelayan Dan Arahan Pemanfaatan Ruang Wilayah Pesisir Di Kecamatan Kragan, Kabupaten Rembang Tahun 2018

\begin{tabular}{llrr}
\hline No & $\begin{array}{c}\text { Arahan } \\
\text { Pemanfaatan } \\
\text { Ruang Wilayah }\end{array}$ & $\begin{array}{c}\text { Luas } \\
\text { (M2) }\end{array}$ & \multicolumn{1}{c}{$\begin{array}{c}\text { Persentase } \\
\text { (\%) }\end{array}$} \\
\hline 1. & $\begin{array}{l}\text { Arahan Kawasan } \\
\text { Budidaya }\end{array}$ & 140.689 & 82,9 \\
& $\begin{array}{l}\text { Arahan Kawasan } \\
\text { 2. }\end{array}$ & & \\
& Lindung & 28.919 & 17,1 \\
\hline & JUMLAH & 169.608 & 100,0 \\
\hline
\end{tabular}

Berdasarkan Tabel 5. analisis luas sertipikasi hak atas tanah nelayan dan arahan pemanfaatan ruang wilayah pesisir Di Kecamatan Kragan, Kabupaten Rembang Tahun 2018 diketahui bahwa untuk luas sertipikat hak atas tanah nelayan di Kecamatan Kragan Kabupaten Rembang yang berada di arahan kawasan budidaya adalah seluas $140.689 \mathrm{M} 2$ atau 82,9\% sedangkan berada di arahan kawasan lindung adalah seluas 28.919 M2 atau 17,1\%.

\section{Simpulan}

Berdasarkan hasil analisis dapat disimpulkan bahwa terdapat sertipikat hak atas tanah nelayan pada arahan pemanfaatan ruang untuk kawasan lindung seluas 28.919 M2 atau 17,1 \%. Hal ini perlu mendapatkan perhatian khusus agar meskipun tanah tersebut telah bersertipikat hak atas tanah namun pemanfaatannya harus mendukung fungsi kawasan lindung supaya tidak terjadi kerusakan ekosistem wilayah pesisir yang berakibat pada masyarakat nelayan itu sendiri.

\section{Ucapan terima kasih}

Ucapan terima kasih disampaikan kepada berbagai pihak yang telah membantu dalam penelitian/penyusunan artikel. Ucapan terimakasih secara khusus disampaikan kepada Danu Eko Agustinova, M.Pd. dan Arif Ashari, M.Sc. yang telah membantu selama proses penerbitan artikel ini.

\section{Referensi}

Cigliano, J. A et al. (2015). Making marine and coastal citizen science matter. Ocean and Coastal Management, 115, 77-87.

Dunstan, P. K et al. (2016). Using ecologically or biologically significant marine areas (EBSAs) to implement marine spatial planning. Ocean and Coastal Management, 121, 116127.

Ferrol-Schulte, D et al. (2015). Coastal livelihood vulnerability to marine resource degradation: A review of the Indonesian national coastal and marine policy framework. Marine Policy, 52, 163-171.

Flego, V dan M. Roić. (2018). Land Tenure Registration On The Marine Areas In Croatia. Ocean \& Coastal Management, 166, 72-81.

Jefferson, $\mathrm{R}$ et al. (2015). Understanding audiences: Making public perceptions research matter to marine conservation. Ocean and Coastal Management, 115, 6170.

Manaf, Murshal. (2012). Analisis Pemanfaatan Ruang di Wilayah Pesisir Kecamatan Bontoharu Kabupaten Kepulauan Salayar. Jurnal Perencanaan Wilayah dan Kota Universitas 45 Makassar. Vol 4, No. dang2 (2015).

Peraturan Daerah Kabupaten Rembang Nomor 14 Tahun 2011 tentang Rencana Tata Ruang 
Wilayah Kabupaten Rembang Tahun 2011 2031.

Peraturan Menteri Agraria dan Tata Ruang/Kepala Badan Pertanahan Nasional Republik Indonesia Nomor 1 Tahun 2018 tentang Pedoman Penyusunan Rencana Tata Ruang Wilayah Provinsi, Kabupaten dan Kota.

Rahmawati, P. (2017). Penyusunan Rencana Zonasi Wilayah Pesisir Di Kabupaten Jepara ( Studi Kasus: Desa Bandengan Kecamatan Jepara ). Tata Loka, 19 (3), 192-205.

Ramadhani, R. (2017). Jaminan Kepastian Hukum Yang Terkandung Dalam Sertipikat Hak Atas Tanah. De Lega Lata, 2, 139-157.

Sutaryono. (2016). Integrasi Urusan Tata Ruang dan Pertanahan: Peluang \& Tantangan Kelembagaan. Yogjakarta : Sekolah Tinggi Pertanahan Nasional Yogyakarta. www.manajemenpertanahan.blogspot.com. Diakses pada tanggal 03 Mei 2019
Undang-Undang No. 5 Tahun 1960 tentang Peraturan Dasar Pokok-Pokok Agraria.

Undang-Undang No. 27 Tahun 2007 tentang Pengelolaan Wilayah Pesisir dan Pulau-Pulau Kecil.

Vugteveen, P et al. (2014). How to structure and prioritize information needs in support of monitoring design for Integrated Coastal Management. Journal of Sea Research, 86, 23-33.

Waryanta. (2016). Integrasi Penataan Pertanahan Dalam Kerangka Penataan Wilayah Pesisir Dan Lahan Atas Terpadu. Jurnal Bhumi, Vol. 2, No.1 (2016).

Wakker, W. J et al. (2003). Land registration and cadastre in the Netherlands, and the role of cadastral boundaries: The application of GPS technology in the survey of cadastral boundaries. Journal of Geospatial Engineering, 5(1), 3-10. 